\title{
Intention to Leave and Associated Factors among Health Professionals in Jimma Zone Public Health Centers, Southwest Ethiopia
}

\author{
Taju Kalifa ${ }^{1}$, Shimeles Ololo² ${ }^{*}$, Fikru Tafese ${ }^{2}$ \\ ${ }^{1}$ Jimma Zone Blood-Bank Office, Jimma City, Ethiopia \\ ${ }^{2}$ Department of Health Economics, Management, and Policy, College of Health Sciences, Jimma University, \\ Jimma City, Ethiopia \\ Email: khalifataju@gmail.com, "shimeles.ololo@ju.edu.et, fikretafese@gmail.com
}

Received 3 September 2015; accepted 25 January 2016; published 28 January 2016

Copyright (C) 2016 by authors and Scientific Research Publishing Inc.

This work is licensed under the Creative Commons Attribution International License (CC BY). http://creativecommons.org/licenses/by/4.0/

(c) $\underset{\mathrm{Er}}{\mathrm{E}}$ Open Access

\section{Abstract}

Background: Inadequate human resources are a major constraint to improving global health. The health sector is characterized by a high turnover coupled with internal as well as external brain drain but there is little information on intention to leave among health professionals in public health centers of Jimma Zone, Oromia Regional State. The aim of this study is to assess intention to leave and associated factors among health professionals in public health centers of Jimma Zone, southwest Ethiopia. Methods: A cross-sectional quantitative and qualitative study was conducted on seven randomly selected woredas (districts) which have 53 public health centers. All health professionals in sampled district public health centers were included $(n=505)$. Factor analysis was employed for all Likert scale instruments to extract factor(s) representing each of the scales using SPSS version 16.0. The qualitative data was analyzed by thematic analysis methods. Ethical approval was obtained from Jimma University. Results: Four hundred fifty five $(\mathbf{9 0 . 1 \%})$ health professionals participated in the study; out of this, $290(63.7 \%)$ had intention to leave. Among variables, job satisfaction (Beta $=-0.298,(95 \% \mathrm{CI},-0.568$ to -0.029$)$, working environment $(\mathrm{Beta}=$ -0.612 , (95\% CI, -0.955 to -0.270$)$, and organizational management $($ Beta $=-0.552,(95 \% \mathrm{CI}$, 0.289 to 0.815 ) had statistically significant association with intention to leave among health professionals in public health centers of Jimma Zone. Conclusions: The overall intention to leave among health professionals was high. Level of job satisfaction, working environment, work pressure, and organizational management had statistically significant association with intention to leave. Thus, responsible bodies should aggressively work on the concerns identified, like, improvements in salary, promotion in terms of training/educational opportunity, improving working environment, and transfer of health professionals, and improvement of the leadership skills of managers.

${ }^{*}$ Corresponding author.

How to cite this paper: Kalifa, T., Ololo, S. and Tafese, F. (2016) Intention to Leave and Associated Factors among Health Professionals in Jimma Zone Public Health Centers, Southwest Ethiopia. Open Journal of Preventive Medicine, 6, 31-41. http://dx.doi.org/10.4236/ojpm.2016.61003 


\section{Keywords}

\section{Intention to Leave, Job Satisfaction, Working Environment, Work Pressure, Organizational Management, Health Professionals, Public Health Centers, Jimma Zone}

\section{Introduction}

Intention to leave is defined as an employee's plan to quit the present job and look forward to finding another job in the near future. The intention of quit is probably the most important and immediate antecedent of turnover decisions [1]. The concept of intention to leave differs from turnover. Turnover refers to the act of individuals actually leaving an organization whereas intention to leave is individuals' perceptions towards leaving. Yet, intention to leave is related to and is an immediate predictor of turnover behavior [2]-[4]. Shortages of the health workers threaten the existence of health facility and negatively influence the quality of local healthcare services where coverage of effective interventions [5]. In order to reduce the magnitude of intention to leave among the employee, the organization must know the main reasons of the employees' intention to leave. In addition to job satisfaction, different factors can positively or negatively influence health workers intention to leave the public health centers such as work pressure, work environment, Organizational management are few factors which need serious consideration to retain health workers in their organization. Intention to leave is an intervening variable between job satisfaction and actual turnover and is therefore affected by individual and organizational factors [1]. When health workers leave their organization, this can negatively affect organizational performance. Organizations have to recruit new health workers and by implication tacit knowledge is lost. Furthermore, organizational turnover could contribute to the shortage of health workers [6]. Studies conducted in other Africa countries indicated in terms of intending to leave their current job 18.8\% [95\% CI: 15.6 - 22.2] of health workers in Tanzania and 26.5\% [95\% CI: 23.7 - 29.5] in Malawi indicated that they were actively seeking employment elsewhere, compared to 41.4\% [95\% CI: 37.3 - 45.1] in South Africa [7].

The reviewed documents showed that in Ethiopia turnover rates in 1999 E.C were $66.7 \%$ for Physicians and $36.8 \%$ for nurses. Oromiya regional state, the largest and most populated region of the country, takes the lion share of the problem of shortage of health professionals at all levels. In the last six years, the public health sectors of the region have lost almost $60 \%$ of its general practitioners and more than $50 \%$ of pharmacists. The demand for quality health care, especially at rural community, is very high. Currently, despite an increasing number of health facilities, the gap with human resource for health is huge. The gap to be covered by available and required health personnel is about $63 \%$. Thus, it was considered as a top priority to take urgent action to curb internal and external migration of health professionals in the region [8]. Due to the fact that intentions are the most immediate determinants of actual behavior they are also of practical value from a research perspective, as once people have actually implemented the behavior to quit; there is little likelihood of gaining access to them to understand their prior situation [1]. The literature on intention to leave among health workers suffers limitations. There are very few studies from low-income and lower middle-income countries and only a handful from upper middle-income countries [9].

According to the evidence from Jimma Zone health office human resource department about $20 \%$ of health workers left Jimma Zone public health centers in the past year [10]; but no study conducted before on the factor associated with intention to leave in this Zone. The establishment of predictors which are important antecedents in the process would give managers the opportunity to intervene before it is too late. Therefore, this study highlights factors associated with intention to leave among health professionals in public health centers in Jimma Zone and the finding of the study will be useful for any concerned bodies to develop effective human resource management strategies that will reduce turnover rate in public health centers.

\section{Methods and Materials}

\subsection{Study Area and Period}

The study was conducted in public health centers of Jimma Zone from April 07-May 07, 2014. Jimma zone is located in Oromia Regional State, southwest Ethiopia. Jimma town is the capital of Jimma Zone located $354 \mathrm{~km}$ 
away from Addis Ababa, the capital city of Ethiopia. The zone is subdivided into 18 woredas (districts) with 555 total Kebeles (the smallest administrative units in the country) and a total population of 2,928,151 (in 2013). Jimma Zone has various public health facilities including, three public hospitals, 106 health centers, 555 health posts with a total of 2373 health workers i.e. $1099 \mathrm{HEW}, 106$ midwives, 659 general nurses, 125 health officers, 110 laboratory technicians and technologists, 112 pharmacy technicians and technologists, 144 environmental health technicians and technologists, 9 medical doctors, and 10 second degree.

\subsection{Study Design}

A cross-sectional study design with quantitative and qualitative methods of data collection was used.

\subsection{Population}

Seven districts were selected randomly among 18 districts of Jimma Zone by lottery method. Fifty three (50\%) public health centers found in seven selected district out of 106 public health centers and all health professionals (505) in sampled public health centers who fulfilled the inclusion criteria were included in the study (Table 1). Purposive sampling technique was used for qualitative data collection.

\subsection{Data Collection Procedures}

Self administered structured questionnaire was used to collect the quantitative data which was developed after reviewing relevant literatures and similar studies and modifications were made in line with the objective of the study and adapted according to the local context [7] [11] and it was prepared in English language and translated to local language (Afan Oromo). The questionnaire consists of socio-demographic questions and different prospective factors of intention to leave; like, work-environment, work pressure, organizational management, and job contents. Determinants of intention to leave were measured by using 5-point Likert-scale. The five alternatives for Likert scale type of questions were coded as strongly disagree $=1$; disagree $=2$; neutral $=3$; agree $=4$ and strongly agree $=5$. In depth interview guide was prepared and used to collect qualitative data .

To facilitate the data collection seven diploma holder data collectors (that is one data collector per each district) and three supervisors were used. Training was given to both data collectors and supervisors for two days on the objective of the study and technique of data collection. Pre-testing of the tools was conducted in a district which was not selected for main study. Qualitative data was collected by principal investigators. A total of sixteen key informants were involved in the in-depth interview. Each in-depth interview was conducted by Afan Oromo for ease of communication, and the transcripts was later translated in to English and finally summarized for write up.

\subsection{Operational Definition and Measurement}

Intention to leave: The extent at which the health workers desire to leave the public health centers. It was measured by five point Likert scale strongly disagree, disagree, neutral, agree, and strongly agree and assessed using

Table 1. List of selected district (woreda), number of health centers and total number of health professionals in selected district.

\begin{tabular}{cccc}
\hline S/No. & Name of selected district & Number of H.C & No. of health professionals \\
\hline 1 & Limu kosa & 6 & 69 \\
2 & Shabe Sombo & 4 & 55 \\
3 & Omo Nada & 10 & 102 \\
4 & Dedo & 13 & 110 \\
5 & Mana & 5 & 48 \\
6 & Goma & 9 & 78 \\
7 & Kersa & 6 & 43 \\
\end{tabular}


three items. The scale was reliable with Cronbach's alpha of 0.89 and KMO $=0.73$. "Presently, I'm actively searching for new job" was the selected factor for subsequent analysis and explained $81.8 \%$ of the total variation of variables in factor analysis.

Job satisfaction: The state of health workers being satisfied by their job. For the purpose of this study, it was rated on 5-point Likert scales, i.e. strongly disagree, disagree, neutral, agree, and strongly agree. The health workers were asked to rate six questions. The scale was reliable with Cronbach's alpha of 0.75 and KMO = 0.7. The items of the scale were subjected to factor analysis to identify the underlying components of job satisfaction. Only two factors with eigen value greater than one were produced. This factor accounted for $68 \%$ of the total variance. Therefore, the items "In general I'm satisfied with this job", and "I feel that I'm able to use my full potential" were considered to be a core ingredient of this scale and used in subsequent analysis.

Work environment: characterized by a pleasant working atmosphere which include relation with colleague and it was measured by five facets. This scale was found to have internal consistency (Cronbach's a $=0.78$ and $\mathrm{KMO}=0.7)$. "I'm satisfied with the recognition I get for the work that I do" was the selected factor for subsequent analysis and explained $60 \%$ of the total variation of variables in factor analysis.

Work pressure: the workload present in the health centers. Four items were used to measure work pressure. The scale had high reliability test of (Cronbach's alpha $=0.8$ and $\mathrm{KMO}=0.71$ ), and only one factor had Eigen value greater than one, and explained $73.9 \%$ of the total variation of variables in factor analysis. The selected factor was "I always finish my work on time" and used during further analysis.

Organizational management: the management style of health centers which include relationship with staff that enable good working conditions. Reliability check showed that the scale has high internal consistency (Cronbach's alpha $=0.89$ and $\mathrm{KMO}=0.82$ ). During factor analysis the scale was reduced to one item "satisfied with management in my health center" with eigenvalue of greater than one. This item explained $73.9 \%$ of the overall variance.

\subsection{Data Analysis}

To ensure data quality, the data was entered using Epi-data entry software, and exported to SPSS version 16 for analysis. The data was re-checked for more errors by running frequency distributions and summarized and organized using appropriate descriptive measures and tables.To determine reliability of the questioner internal consistency test with Cronbach's alpha was used for each dimension included in this study because low reliability results in some errors. Cronbach's alpha greater than 0.7 , was taken as acceptable level, and those scales with Cronbach's alpha value $>=0.7$ was subjected to factor.

Only those with Eigen value greater than one were considered in subsequent analysis. Factor score was computed for the item identified to represent the intention to leave by varimax rotation method. Using this regression factor score, multivariate linear regression analysis was performed and the effect of independent variables on the regression factor score of the dependent variable was quantified. Finally, explanatory variables which had statistically significant association with the dependent variable $(\mathrm{P}<0.05)$ were entered to the final regression model.

The analysis of qualitative data was based on an inductive approach geared to identifying patterns in the data by means of thematic codes and categories was analyzed by thematic analysis technique descriptively.

\subsection{Ethical Consideration}

Ethical clearance was obtained from Jimma University College of public health and medical sciences Ethical Review Board. Official letter was written to Jimma Zone Health Office by Jimma University, and consequently Jimma Zone Health Office wrote to each selected districts health office. Before the interview, each respondent was informed of the aim of the study, the possible benefit from the study and confidentiality. Informed verbal consent was obtained individually, and any respondent was assured that they have a full right to refuse to participate whether in the beginning or in the middle of the interview without any negative connotation on their future service.

\section{Results}

\subsection{The Socio-Demographic Characteristics of Health Professionals}

From 505 health professionals who had received structured questionnaires, 455 responded fully to all questions, 
and the remaining 50 were excluded due to incomplete information they gave, that made the response rate $90.1 \%$. The age of the respondents ranged from 19 to 56 years, and the mean age was 27 years with SD $=5.23$. Majority of the respondents (63.1\%) were male, and 51.4\% were single. Two hundred and nine (45.9\%) were nurses, and $61.8 \%$ were diploma holders. Three fourth (344) of the respondents had work experience of five years with minimum of 1 year and maximum of 32 years with mean work experience of 5 years. In addition, 1114 and 3863 Birr were the minimum and the maximum monthly salary of the respondents respectively, with the mean monthly salary of 1979 Birr. Moreover, the minimum and maximum monthly allowances were 0 and 1200 Birr respectively, with the median of 300 Birr (Table 2).

\subsection{Intention to Leave among Health Professionals}

The overall mean score of intention to leave among health professionals in public health centers of Jimma zone

Table 2. The socio-demographic characteristics of health professionals in Jimma Zone, Oromia Regional State, southwest Ethiopia, 2014.

\begin{tabular}{|c|c|c|}
\hline Variable $(n=455)$ & Frequency & Percentage \\
\hline \multicolumn{3}{|l|}{ Age group (years) } \\
\hline $20-25$ & 176 & 38.7 \\
\hline $26-30$ & 208 & 45.7 \\
\hline $31-35$ & 39 & 8.6 \\
\hline $36-40$ & 18 & 4.0 \\
\hline $41-45$ & 7 & 1.5 \\
\hline$>45$ & 7 & 1.5 \\
\hline \multicolumn{3}{|l|}{ Sex } \\
\hline Male & 287 & 63.1 \\
\hline Female & 168 & 36.9 \\
\hline \multicolumn{3}{|l|}{ Marital status } \\
\hline Single & 234 & 51.5 \\
\hline Married & 218 & 47.9 \\
\hline Divorced & 1 & 0.2 \\
\hline Widowed & 2 & 0.4 \\
\hline \multicolumn{3}{|l|}{ Work experience } \\
\hline $0-5$ & 344 & 75.6 \\
\hline $6-10$ & 74 & 16.3 \\
\hline $11-15$ & 8 & 1.8 \\
\hline $16-20$ & 13 & 2.9 \\
\hline $21-25$ & 9 & 2.0 \\
\hline$>25$ & 7 & 1.5 \\
\hline \multicolumn{3}{|l|}{ Educational status } \\
\hline Diploma & 281 & 61.8 \\
\hline Degree & 173 & 38.0 \\
\hline MPH/Msc. & 1 & 0.2 \\
\hline \multicolumn{3}{|l|}{ Profession } \\
\hline Nurse & 209 & 45.9 \\
\hline Midwife & 59 & 13.0 \\
\hline Laboratory & 67 & 24.7 \\
\hline Health officer & 40 & 8.8 \\
\hline Pharmacy & 46 & 10.1 \\
\hline Env. Health & 34 & 7.5 \\
\hline \multicolumn{3}{|l|}{ Monthly Salary } \\
\hline$<1500$ & 174 & 38.2 \\
\hline $1500-2499$ & 146 & 32.1 \\
\hline $2500-3499$ & 132 & 29.0 \\
\hline$>3500$ & 3 & 0.7 \\
\hline \multicolumn{3}{|l|}{ Monthly allowance } \\
\hline$<500$ & 396 & 87.0 \\
\hline $500-1000$ & 56 & 12.3 \\
\hline $1001-1500$ & 2 & 0.4 \\
\hline$>1500$ & 1 & 0.2 \\
\hline
\end{tabular}


were $63.7 \%$. Of this, $25.9 \%$ reported to leave within the coming one year, $19.8 \%$ after one year, and $18 \%$ when they get better jobs (Table 3).

\subsection{Socio-Demographic Predictors of Intention to Leave among Health Professionals}

The relationship between socio-demographic variables and intention to leave factor score is quantified in Table 4. While monthly salary, type of profession, and age of the health workers were among the socio-demographic variables which were candidate for multivariate analysis. Accordingly, health professionals' whose age were within 31 - 35 years had an average 0.693 decrease intentions to leave score than those health professionals' whose ages were between 26 - 30 (95\%CI, -1.028 to -0.358), and likewise, those who had monthly salary between 1500 to 2499 Birr had a decreased intention to leave score by 0.24 compared to those whose monthly salary were below 1500 Birr (95\%CI, -0.46 to -0.02 ); Moreover, midwives had 0.346 units decreased intention to leave as compared to nurses (95\%CI, -0.654 to -0.038 ) (Table 4).

\subsection{Job Related Predictors of Intention to Leave among Health Professionals}

The entire variables such as job satisfaction, work environment, work pressure and organizational management were undertaken for factor analysis, and only:

- In general I'm satisfied with this job,

- I'm able to use my full potential,

- I'm satisfied with the recognition I got for the work that I do,

- I always finish my work on time, and

- I'm satisfied with the management in my health centers were extracted by factor analysis (Table 5).

Among the factors used to measure job satisfaction "in general I'm satisfied with this job" was statistically significant association with intention to leave, and health professionals who were strongly agree in job satisfaction had 0.298 an average decrease in intention to leave score compared to those who somewhat agreed (95\%CI, -0.568 to -0.029 ).

These findings were supported by qualitative finding as follows. Accordingly, all in-depth interviewed health professionals reported that they were not satisfied with their job.

A 25 years old laboratory technologist said, "I have served for three years in this health center but I remember I was participated only in TB-diagnosis training one year before, do you think is that enough to provide quality service to the people? I don't think.....”.

Most of the interviewed health professionals in health centers shared this idea.

A 24 years clinical nurse in one of health center said, "The payment is completely inadequate how can one live on 1233 Birr per month! This is the main reason that aggravate health workers intention to leave".

A head of one district health office said, "According to our district, health professionals had high intention to leave the public health centers due to unmet needs, like, promotion, transfer, education and training, these were affecting in providing quality service to the people since dissatisfied health workers don't provide quality service." This idea shared by a number of district health office heads, which was described as health professionals were overloaded and this could cause people to lose interest in the work and all wanted to leave if they got better job.” (A 29 year health officer)

There was significant association between intention to leave and working environment. Health professionals who strongly agreed in a statement "I'm satisfied with the recognition I got for the work that I did" had an aver-

Table 3. Intention to leave among health professionals in Jimma Zone, 2014.

\begin{tabular}{lcc}
\hline Variable $(\mathbf{n}=\mathbf{2 9 0 / 4 5 5 )}$ & Frequency & Percentage \\
\hline When do you think to leave & & 25.9 \\
Within one year & 118 & 90 \\
After one year & 82 & 19.8 \\
Other (when I got better jobs) & $\mathbf{2 9 0}$ & $\mathbf{6 3 . 7}$ \\
Total & $\mathbf{2 9 0}$ \\
\hline
\end{tabular}


Table 4. Socio demographic predictors of intention to leave among health professionals in Jimma Zone, Oromiya Regional State, southwest Ethiopia, 2014.

\begin{tabular}{|c|c|c|c|c|c|c|}
\hline \multirow{2}{*}{ Variable $(n=455)$} & \multirow{2}{*}{ No. (\%) } & \multirow{2}{*}{$\begin{array}{l}\text { Unstandardized } \\
\text { coefficient Beta }\end{array}$} & \multirow{2}{*}{$\begin{array}{l}\text { standardized } \\
\text { coefficient Beta }\end{array}$} & \multirow{2}{*}{ P-value } & \multicolumn{2}{|c|}{$95 \%$ CI for B } \\
\hline & & & & & Lower bound & Upper bound \\
\hline \multicolumn{7}{|l|}{ Profession } \\
\hline Midwife & $59(13)$ & -0.346 & -0.116 & 0.028 & -0.654 & -0.038 \\
\hline Laboratory & $67(24.5)$ & 0.007 & 0.003 & 0.960 & -0.282 & 0.296 \\
\hline Health off & $40(8.8)$ & 0.100 & 0.028 & 0.603 & -0.279 & 0.480 \\
\hline Pharmacy & $46(10.1)$ & 0.191 & 0.058 & 0.266 & -0.146 & 0.527 \\
\hline Env. Health & $34(7.5)$ & 0.191 & 0.050 & 0.316 & -0.183 & 0.564 \\
\hline \multicolumn{7}{|l|}{ Age in year } \\
\hline $20-25$ & 176 (38.7) & 0.283 & -0.138 & 0.005 & -0.480 & -0.086 \\
\hline $26-30^{*}$ & 208 (47.5) & & & & & \\
\hline $31-35$ & $39(8.6)$ & -0.693 & -0.198 & 0.000 & -1.028 & -0.358 \\
\hline $36-40$ & $18(4)$ & -0.729 & -0.142 & 0.003 & -1.201 & 0.257 \\
\hline $41-45$ & $7(1.5)$ & 0.059 & 0.007 & 0.879 & -0.796 & 0.681 \\
\hline$>45$ & $7(1.5)$ & 0.017 & 0.002 & 0.965 & -0.755 & 0.722 \\
\hline \multicolumn{7}{|l|}{ Work experience } \\
\hline $0-5^{*}$ & 344 (75.6) & & & & & \\
\hline $6-10$ & 74 (16.3) & 0.056 & 0.021 & 0.697 & -0.225 & 0.337 \\
\hline $11-15$ & $8(1.8)$ & 0.126 & 0.017 & 0.749 & -0.648 & 0.900 \\
\hline $16-20$ & $13(2.9)$ & -0.094 & -0.016 & 0.792 & -0.798 & 0.609 \\
\hline $21-25$ & $9(2)$ & -0.934 & -0.130 & 0.073 & -1.956 & 0.088 \\
\hline$>25$ & $7(1.5)$ & -0.126 & -0.016 & 0.829 & -1.274 & 1.021 \\
\hline \multicolumn{7}{|l|}{ Marital status } \\
\hline Single* & 234 (51.4) & & & & & \\
\hline Married & 218 (47.9) & 0.017 & 0.009 & 0.866 & -0.182 & 0.216 \\
\hline Divorced & $1(0.2)$ & -0.646 & -0.030 & 0.551 & -2.774 & 1.482 \\
\hline widowed & $2(0.4)$ & 1.117 & 0.074 & 0.110 & -0.253 & 2.487 \\
\hline \multicolumn{7}{|l|}{ Monthly salary } \\
\hline$<1500^{*}$ & 174 (38.2) & & & & & \\
\hline $1500-2499$ & $146(32.1)$ & -0.240 & -0.112 & 0.202 & -0.460 & -0.020 \\
\hline $2500-3499$ & 132 (29) & -0.067 & -0.031 & 0.030 & -0.294 & 0.159 \\
\hline$>3500$ & $3(0.7)$ & -0.034 & -0.003 & 0.560 & -1.176 & 1.108 \\
\hline \multicolumn{7}{|l|}{ Allowance } \\
\hline$<500^{*}$ & 396 (87) & & & & & \\
\hline $500-1000$ & $56(12.3)$ & -0.043 & -0.014 & 0.772 & -0.335 & 0.249 \\
\hline $1001-1500$ & $2(0.4)$ & -0.250 & -0.017 & 0.736 & -1.706 & 1.207 \\
\hline$>1500$ & $1(0.2)$ & 0.713 & 0.033 & 0.471 & -1.230 & 2.655 \\
\hline \multicolumn{7}{|l|}{ Education } \\
\hline Diploma ${ }^{*}$ & 281 (61.8) & & & & & \\
\hline Degree & $174(38.2)$ & 0.136 & 0.021 & 0.430 & -0.202 & 0.474 \\
\hline \multicolumn{7}{|l|}{ Sex } \\
\hline Male $^{*}$ & 287 (63.1) & & & & & \\
\hline female & 168 (36.9) & -0.048 & -0.023 & 0.634 & -0.247 & 0.151 \\
\hline
\end{tabular}

*reference category.

age 0.612 decrease intention to leave score compared to their counterpart respondents strongly disagreed (95\% CI, -0.270 to -0.955$)$.

Majority of the interviewed health professionals also complained about work environment. They reported that there were no good work environments that could motivate them to provide quality services; rather plenty of bottlenecks overwhelmed the health centers.

"The supply is inadequate in the health center, even laboratory services were interrupted sometime for a week or a month due to lack of reagent, no one is ready to listen you solve the problem immediately, the response of people in a position is always the same, lack of budget, so you have no option" said a 26 year old female laboratory technician in one of health center. Likewise a 25 years old Pharmacist in one of rural health center said, 
Table 5. Final predictors of intention to leave among health professionals in Jimma Zone, Oromiya Regional State, southwest Ethiopia, 2014.

\begin{tabular}{|c|c|c|c|c|c|c|}
\hline \multirow{2}{*}{ Variable $(n=455)$} & \multirow{2}{*}{ No. (\%) } & \multirow{2}{*}{$\begin{array}{c}\begin{array}{c}\text { Unstandardized } \\
\text { coefficient }\end{array} \\
\text { Beta }\end{array}$} & \multirow{2}{*}{$\begin{array}{c}\text { standardized } \\
\text { coefficient } \\
\text { Beta }\end{array}$} & \multirow{2}{*}{ P-value } & \multicolumn{2}{|c|}{$95 \%$ CI for B } \\
\hline & & & & & Lower bound & Upper bound \\
\hline \multicolumn{7}{|c|}{$\begin{array}{l}\text { I'm able to use my full } \\
\text { potential }\end{array}$} \\
\hline strongly disagree & $66(14.5)$ & 0.292 & -0.214 & 0.054 & -0.005 & 0.588 \\
\hline disagree & $82(18)$ & -0.106 & -0.041 & 0.453 & -0.383 & 0.171 \\
\hline neutral & 64 (14.1) & -0.241 & -0.041 & 0.115 & -0.540 & 0.059 \\
\hline agree $^{*}$ & $124(27.3)$ & & & & & \\
\hline strongly agree & 119 (26.2) & -0.214 & -0.094 & 0.093 & -0.463 & 0.036 \\
\hline \multicolumn{7}{|c|}{$\begin{array}{l}\text { I'm satisfied with this } \\
\text { jobs }\end{array}$} \\
\hline strongly disagree & $66(14.5)$ & 0.278 & 0.109 & 0.100 & -0.054 & 0.609 \\
\hline disagree & $82(18)$ & 0.256 & 0.086 & 0.122 & -0.069 & 0.581 \\
\hline neutral & $64(14.1)$ & 0.238 & 0.089 & 0.110 & -0.055 & 0.531 \\
\hline agree $^{*}$ & 124 (27.3) & & & & & \\
\hline strongly agree & 119 (26.2) & -0.298 & -0.130 & 0.030 & -0.029 & -0.568 \\
\hline \multicolumn{7}{|c|}{$\begin{array}{l}\text { I'm satisfied for the } \\
\text { recognition I get for the } \\
\text { work that I do** }\end{array}$} \\
\hline strongly disagree & $136(29.9)^{*}$ & & & & & \\
\hline disagree & $91(20)$ & -0.269 & -0.108 & 0.030 & -0.010 & -0.528 \\
\hline neutral & $66(14.5)$ & -0.387 & -0.136 & 0.012 & -0.086 & -0.687 \\
\hline agree & 107 (23.5) & -0.393 & -0.167 & 0.007 & -0.108 & -0.677 \\
\hline strongly agree & $55(12.5)$ & -0.612 & -0.200 & 0.000 & -0.270 & -0.955 \\
\hline \multicolumn{7}{|c|}{$\begin{array}{l}\text { I always finish my work } \\
\text { on time }\end{array}$} \\
\hline strongly disagree & $18(4.0)$ & 0.369 & 0.072 & 0.106 & -0.079 & 0.818 \\
\hline disagree & $41(9)$ & 0.172 & 0.049 & 0.294 & -0.150 & 0.494 \\
\hline neutral & 59 (13) & -0.056 & -0.019 & 0.706 & -0.345 & 0.234 \\
\hline agree $^{*}$ & 179 (39.3) & & & & & \\
\hline strongly agree & $158(34.7)$ & -0.383 & 0.182 & 0.001 & -0.167 & -0.599 \\
\hline \multicolumn{7}{|c|}{$\begin{array}{l}\text { I'm satisfied with the } \\
\text { management in my } \\
\text { health center }\end{array}$} \\
\hline strongly disagree & $80(17.6)$ & 0.552 & 0.210 & 0.000 & 0.289 & 0.815 \\
\hline disagree $^{*}$ & $124(27.3)$ & & & & & \\
\hline neutral & 83 (18.2) & -0.235 & -0.091 & 0.102 & -0.516 & 0.047 \\
\hline agree & $112(24.6)$ & 0.028 & 0.012 & 0.833 & -0.233 & 0.289 \\
\hline strongly agree & $56(12.3)$ & -0.192 & -0.063 & 0.257 & -0.524 & 0.140 \\
\hline
\end{tabular}

* reference category, ** represent job satisfaction, working environment, work pressure, and organizational management respectively.

"everyday more than $25 \%$ of the prescription in the health center is written to rural drug venders, no one gives attention to solve the problem, how can you tolerate this type of working environment?"

Health professionals' who were strongly agree in the factor "I always finish my work on time" had an average of 0.383 units decreased intention to leave score than those who agreed (95\% CI, -0.167 to -0.599 ). A qualitative finding that strengthen this idea was reported by a 29 year BSc holder nurse in one of town health center as they were working beyond their capacity in the health center; they didn't even have time for lunch, this affect quality of service and increase their intention to leave.

This response is contradicted with a response of female nurse in one of rural health center. She said, "In this health center no adequate work; patient flow per day is below what you expected to do per day; most of the health workers in this health center spent their time sitting here and there, but no one allows you to go where you want outside this health center".

Among health professionals who strongly disagreed in organizational management had 0.552 units increased intention to leave score when compared with those who somewhat disagreed (95\% CI, 0.289 to 0.815 ). The results of qualitative finding support this idea. "The management system of our health center is not good; always 
partiality is observed in every activity, this demoralized us" said by a 27 year midwife in one health center. Likewise, "People in a position always treat workers differently whether by relation, being a friend, or some other kinds; even training is not provided by your right position; please leave me, it is better to keep silent until we leave this health center" said a 26 year nurse in one health center.

One the other hand, one manager in department of human resource for health said, "the complain of health professionals are transfer and promotion from rural health centers to large towns but this opportunity is now limited because large towns are almost saturated, health professionals in a district don't understand this, they always chant poor management. This has enormous effect in providing quality service because always their intention is to leave health centers, not to provide quality service."

\section{Discussion}

Health professionals are a strategic capital in health service organizations where the various clinical, managerial, technical, and other personnel are the principal inputs making it possible for most health interventions to be performed. The study attempted to identify the perception, insights, and opinions of health professionals on the intention to leave the public health centers.

Of 455 health professionals' who replied to the questionnaire, $63.7 \%$ had intention to leave; out of these, $25.9 \%$ wanted to leave within one year, $19.8 \%$ after one year, and $18 \%$ after they get better jobs. The current finding shows that the problem is much higher than the studies conducted in other African countries where $18.8 \%$ (95\% CI: 115.6_22.2) of health workers in Tanzania, 26.5\% (95\% CI: 23.7_29.5) in Malawi, and 41.4\% (95\% CI: 37.3_45.1) in South Africa had intention to leave [7]. The difference could be resulted from on-going intervention to address this problem in all the three countries by gathering better information on job satisfaction. On top of these, another study conducted in Senegal mid-wife indicated that $43.2 \%$ reported that they had intention to leave, and $41.6 \%$ said they would probably try to leave before the end of the year, and $17.3 \%$ said they wanted to leave right away [12]. The difference may be raised from that these study done in hospitals, only on single discipline of health professionals, and it was a longitudinal study. This idea was in line with qualitative finding in which most of the health professionals had intention to leave due to unmet needs, like promotion, education and training opportunity present in public health centers.

Studies revealed that increase in age decreases the intention to leave which is consistent with the finding suggested that when age, experience, and tenure in an organization increases, the desire to leave decreases [13]. It's also consistent with the study conducted in Tanzania; intention to leave decreased significantly with age. The odds of leaving in the over 50 age group were half of those under 30 years [7].

Level of salary was significantly associated with the scores of intention to leave, health professionals' with lower salary had higher intention to leave than those with higher salary. This finding is similar with the study conducted in Saudi nurses; level of salary was significantly associated with the scores of turnover intention. Nurses with lower salary demonstrated higher intent of turnover than higher salary employees [12].

Among the variable used in the study to measure intention to leave, organizational management account higher contribution for intention to leave which was negatively correlated in liner regression. Among the respondents, 50.5\% were unhappy with the organizational management system of health center which had increased their intention to leave score. This study were comparable with the study conducted in East Hararge Zone; more than half of the respondents (51.8\%) revealed that poor management and leadership skills at different levels took the highest share for cause of staff frustration and attrition. More than three-quarter (76.2\%) of respondents were not happy with overall management of their health sectors [14].

The qualitative study shows that almost all health professionals reported as the management system of their health centers were poor and occupied by partiality that enhanced their intention to leave public health centers.

The other possible factor affecting intention to leave was the working environment. Health professionals who have satisfied with working environment had an average 0.612 decrease in intention to leave score.

A good working atmosphere is characterized by a pleasant interaction with colleagues working in the same unit, a good team spirit, appreciation of good performance and collegial behavior. A study conducted in Taiwan indicated that when nurses in long term care experience an unpleasant working atmosphere, this would increase their intention to leave their organization [15]. Even though this study conducted only in nurses, it is in line with this finding. The qualitative finding also indicated that the health professionals were unhappy with working environment in which there was no adequate equipment, drugs and reagents for laboratory services. 
Among respondent, only 37.5\% were satisfied with their job. This finding is lower than the findings in other African countries, where $82.3 \%$ of health professionals in Tanzania satisfied with their jobs, $71.0 \%$ in Malawi, and $52.1 \%$ in South Africa [7]. The observed differences may be due to the timely information gathered on health professionals job satisfaction in all the three countries; and another study conducted in the United States presented evidence showing that dissatisfied nurses were $65 \%$ more likely to have intent to leave compared to their satisfied counterparts [16]. The indicated difference may be resulted from the difference in economic and infrastructure of health sectors. The qualitative findings also indicated that the health professionals were not satisfied with their jobs due to unsatisfactory salary and benefits present in public health centers.

Considering work pressure, when health workers experience more work pressure, it could increases their intention to leave their current organization [17]. The result of this finding shares the same evidence as work pressure had an average increase of intention to leave score by 0.383 units. This finding is consistent with the study conducted in United States where nurses who intended to stay in their job experienced significantly less work pressure than people who had intention to leave their job [17]. The strength of this study is application of both quantitative and qualitative methods of data collection in order to complement or triangulate each other.

\section{Conclusion}

The overall intention to leave among health professionals was high. Job satisfaction, working environment, work pressure and organizational management have statistically significant association with intention to leave among health workers in public health centers of Jimma Zone. Thus responsible bodies should aggressively work on the concerns identified like salary, promotion in terms of training/education opportunity, working environment, and transfer of health professionals, and improvement of the leadership skills of managers that enable good working conditions. On the other hand, since this study focused only on variables that are related with health professionals and working environment, we recommend other variables, such as, social environment and infrastructure of the area to be addressed in further studies.

\section{Acknowledgements}

We acknowledge Jimma Zone Health Office for their cooperation on provision of health human resource information of the zone. Besides, we thank all study participants including health institutions participated in this study for their cooperation and efforts to facilitate the data collection processes.

\section{Competing Interests}

The authors declare that they have no competing interests.

\section{Authors' Contributions}

T.K. designed the study, coordinated data collection, analysis, interpretation, and write-up, drafted the manuscript. S.O. participated in study design, and critically revised the manuscript. F.T. participated in study design, and critically revised the manuscript. All authors read and approved the final version of the manuscript.

\section{References}

[1] Price, J.L. and Mueller, C.W. (1981) A Causal Model of Turnover for Nurses. Academy of Management Journal, 24, 543-565. http://dx.doi.org/10.2307/255574

[2] Lee, H.W. and Liu, C.H. (2007) An Examination of Factors Affecting Repatriates' Turnover Intentions. International Journal of Manpower, 28, 122-134. http://dx.doi.org/10.1108/01437720710747956

[3] Randall, D.M. (1990) The Consequences of Organizational Commitment: Methodological Investigation. Journal of Organizational Behavior, 11, 361-378. http://dx.doi.org/10.1002/job.4030110504

[4] Somers, M.J. (1995) Organizational Commitment, Turnover and Absenteeism: An Examination of Direct and Interaction Effects. Journal of Organizational Behavior, 16, 49-48. http://dx.doi.org/10.1002/job.4030160107

[5] Anand, S. and Bärnighausen, T. (2007) Health Workers and Vaccination Coverage in Developing Countries: An Econometric Analysis. The Lancet, 369, 1277-1285. http://dx.doi.org/10.1016/S0140-6736(07)60599-6

[6] Tummers, L.G., Groeneveld, S.M. and Lankhaar, M. (2013) Why Do Nurses Intend to Leave Their Organization? A 
Large-Scale Analysis in Long-Term Care. Journal of Advanced Nursing, 69, 2826-2838. http://dx.doi.org/10.1111/jan.12249

[7] Blaauw, D., et al. (2013) Comparing the Job Satisfaction and Intention to Leave of Different Categories of Health Workers in Tanzania, Malawi, and South Africa. Global Health Action, 6, 19287.

[8] FMoH, Ethiopia (2006) Best Practice in Health. First National Workshops: Regional Presentations, Addis Ababa.

[9] Rouleau, D., Fournier, P., Philibert, A., Mbengue, B. and Dumont, A. (2012) The Effects of Midwives' Job Satisfaction on Burnout, Intention to Quit and Turnover: A Longitudinal Study in Senegal. Human Resources for Health, 10, 9. http://dx.doi.org/10.1186/1478-4491-10-9

[10] Jimma Zone Health Office (2013) Annual report of Human Resource for Health of the Zone Health Office.

[11] Masroor, A.M. and Fakir, M.J. (2010) Level of Job Satisfaction and Intent to Leave among Malaysian Nurses. Business Intelligence Journals, 3, 123-137.

[12] Almalki, M.J., et al. (2012) The Relationship Between Quality of Work Life and Turnover Intention of Primary Health Care Nurses in Saudi Arabia. BMC Health Services Research, 12, 314. http://dx.doi.org/10.1186/1472-6963-12-314

[13] Beecroft, P.C., Dorey, F. and Wenten, M. (2007) Turnover Intention in New Graduates Nurses: A Multivariate Analysis. Journal of Advanced Nursing, 62, 42-52.

[14] Jundi, A. and Mitikie, G. (2012) Assessment of the Magnitude, Patterns and Determinant Factors of Health Worker Migration from the Public Health Sectors: A Descriptive Case Study in East Hararghe Zone of Oromiya, Eastern Ethiopia. Eastern Ethiopia, Addis Ababa University Digital Library. http://hdl.handle.net/123456789/3279

[15] Tzeng, H.M. (2002) The Influence of Nurses' Working Motivation and Job Satisfaction on Intention to Quit: An Empirical Investigation in Taiwan. International Journal of Nursing Studies, 39, 867-878. http://dx.doi.org/10.1016/S0020-7489(02)00027-5

[16] Shields, M.A. and Ward, M. (2001) Improving Nurse Retention in the National Health Service in England: The Impact of Job Satisfaction on Intention to Quit. Journal of Health Economics, 20, 677-701. http://dx.doi.org/10.1016/S0167-6296(01)00092-3

[17] Karsh, B., Booske, B.C. and Sainfort, F. (2005) Job and Organizational Determinants of Nursing Home Employee Commitment, Job Satisfaction and Intent to Turnover. Ergonomics, 48, 1260-1281. http://dx.doi.org/10.1080/00140130500197195

\section{Abbreviation}

FMOH: Federal Ministry of Health

HEW: Health extension workers

HIC: High income country

HRH: Human resource for health

JZHO: Jimma Zone Health Office

LIC: Low Income County

LMICs: Low and middle-income countries

MDG: Millennium development goal

WHO: World health organization

SD: Standard deviation

SPSS: Statistical Package for Social Sciences 